\title{
Digital literacy practices of Turkish pre-service EFL teachers
}

Sedat Akayoğlu

Bolu Abant İzzet Baysal University, Turkey

H. Müge Satar

Newcastle University, United Kingdom

Kenan Dikilitaş

Bahçeşehir University, Turkey

Nazlı Ceren Cirit

İstanbul University, Turkey

Sibel Korkmazgil

Sivas Cumhuriyet University, Turkey

With rapid changes in information and communication technologies, it is no longer sufficient for language teachers and pre-service teachers (PTs) to know how to use existing digital tools. They also need to be digitally literate in order to critically evaluate such tools and platforms for safe, wise, and productive use. Within a qualitative approach, this study investigated Turkish PTs' conceptualisation of digital literacy. This included an exploration of how PTs defined this concept, what kind of tools they used, and for which purposes they preferred to use digital tools. First, we found that PTs concept of digital literacy consist of many levels from knowledge to use, and to critical, creative, and collaborative use. Second, we observed that university professors play an important role in the development of digital literacy levels of PTs. Third, it was found that PTs use social media platforms heavily for various purposes, however, we identified a need for further guidance in supporting PTs' use of these platforms for their professional development. The findings of this study shed light on the current digital literacy skills of PTs in Turkey and will be beneficial for educational policy makers and teacher trainers in teacher education for the twenty-first century.

\section{Implications for practice or policy:}

- Language teacher educators should engage pre-service teachers first in understanding pedagogical purposes of digital tools and then how they may address these purposes.

- Language teacher educators should model the integration of digital tools in teaching contexts.

- Pre-service teacher education programs should combine technology-related courses with pedagogy and digital material design.

Keywords: digital literacy, pre-service teachers, pedagogy, thematic analysis, language teaching

\section{Introduction}

As communication around the globe becomes increasingly digitally mediated, language teachers' responsibility extends beyond teaching linguistic skills. Today, language learners need to activate their digital skills in order to engage in effective communication in the electronically connected world. Dudeney and Hockly (2016) define this new set of digital skills as follows:

An umbrella term for these new skills and competences, digital literacies and the concept of being digitally literate refers to our ability to effectively make use of the technologies at our disposal. This includes not just technical skills, but perhaps more importantly, an awareness of the social practices that surround the appropriate use of new technologies. (p. 115) 
The development of digital literacy skills is a widely acknowledged teaching goal in many language programs (Godwin-Jones, 2015). According to Dooly and O'Dowd (2012), as concepts of proximity and reality become ambiguous in digitally-mediated social worlds, language learners need to skillfully combine their linguistic and digital skills in order to collaborate and function in these new environments. Similarly, Pegrum (2011) argued that individuals "who lack appropriate literacies barely exist in digital culture and are doomed to hover on the fringes of digital societies and digital economies" (pp. 9-10). While mediation through technology opens up possibilities for "new kinds of social encounter, new kinds of communities, and new prospects for learning" (Kern, 2014, p. 340), it also presents foreign language learners with considerable challenges as "multimodal texts that incorporate sound, graphics, animation, or video demand more symbolic sophistication and more critical thinking than ever if students are to resist being lulled into passive reception" (Kern, 2014, p. 341). Likewise, Kurek and Hauck (2014) emphasise language learners' need for digital and participatory literacy skills so that they can actively participate in and contribute to online communities as semiotic initiators through an informed use of available semiotic resources. This pressing need to develop not only linguistic and pragmatic knowledge and skills but also "a disposition for paying critical attention to the culturally encoded connections among forms, contexts, meanings, and ideologies in a variety of material mediums" is reiterated by Chun, Kern, and Smith (2016, p. 66).

Moreover, digital literacy is also accepted as a fundamental component in blended learning settings where success of the blended learning environment is determined by the digital literacy practices of the learners (Tang \& Chaw, 2016). Therefore, increasingly digital and multimodal communication (Bezemer \& Kress, 2016) coupled with the relevance of twenty-first century skills in education and particularly in teacher education makes exploration of prospective language teachers' digital literacy skills a timely research agenda. An investigation of their current digital skills and literacy practices can assist in identification of their needs, which could then guide initiatives to revise foreign language teacher education curricula.

The aims of this study were twofold. First, we explored pre-service language teachers' understanding of digital literacies to achieve a conceptualisation of what it means to be digitally literate. Second, we investigated Turkish pre-service language teachers' digital literacy practices in an attempt to present their perception of the range of skills that they can readily incorporate in their everyday lives and future teaching experiences and the ones that require improvement.

\section{Research questions}

In parallel with the purpose of the study, the following research questions were posed:

1. What does the term digital literacies mean for pre-service English language teachers?

2. What digital tools do pre-service English language teachers use?

3. For what specific purposes do PTs use digital tools in teaching English?

\section{Literature review}

In addition to traditional literacies, that is the three Rs: reading, 'riting and 'rithmetic (Dudeney \& Hockly, 2016), the term digital literacies, or new media literacies, describes meaning-making practices that are accomplished via digital media. The plural use of the term literacies, denotes variation in semiotic practices across time periods, contexts, communities, and cultures. The concept of multiliteracies acknowledges not only the linguistic and cultural plurality, but also increasingly multimodal expression of meaning in electronic communication (see Thorne [2013] for a comprehensive discussion of the origins and implications of the terms literacy, literacies, multiliteracies, and digital literacies).

Arguments for a pedagogy of multiliteracies gained prominence in education in 1996 when The New London Group published a manifesto emphasising a shift in meaning-making. This shift has been taking place alongside the emergence of new media in which new ways of production and consumption of texts as well as establishment and maintenance of identities and relationships are observed. New digital media have altered the scale, frequency, and space of human interaction as people can now communicate with larger numbers of physically distant people more often using various forms of social media (Thorne, 2013). New media has also had implications on knowledge co-construction and collaboration reflecting the pedagogical shift from cognitive to socio-constructivist theories of learning (Thorne, 2013). 


\section{Definition and components of digital literacy/ies}

Whilst the value in and need for developing language learners' and teachers' digital literacy practices is widely accepted, there seems to be little consensus on what being digitally literate means, how it can be measured, and the procedures involved in developing these literacies. There are many definitions of digital literacy and there is considerable diversity over what constitutes digital literacy. Lankshear and Knobel (2008) distinguish between conceptual and standardised operational definitions of digital literacies. While conceptual definitions present an ideal, standardised operational definitions focus on the tasks, performances, or skills. Acknowledging the vast diversity in understandings and definitions of digital literacy, Lankshear and Knobel (2008) suggest digital literacy as a framework that brings together many sub-literacies and skills. They argue that "any attempt to constitute an umbrella definition or overarching frame of digital literacy will necessarily involve reconciling the claims of myriad concepts of digital literacy, a veritable legion of digital literacies" (p. 4).

Drawing on Dudeney, Hockly, and Pegrum (2013), Dudeney and Hockly (2016) defined digital literacies as "the ability of people to know how to operate these [digital] technologies, and to use them safely, wisely and productively" (p. 115). In this paper, we adopt this definition of digital literacies as a starting point for two reasons. First, it involves the plural use of the term suggesting variation in semiotic practices among different cultures and languages as well as through various digital modes. Second, Dudeney and Hockly (2016) present the concept in relation to foreign language learning settings. The taxonomy of digital literacies proposed by Dudeney et al. (2013) is divided into four main areas: language, information, connections, and (re)design (as summarised in Dudeney and Hockly, 2016). The sub-categories for each of these four main areas are as follows:

- Language: print literacy, texting literacy, hypertext literacy, visual media and multimedia literacy, gaming literacy, mobile literacy, code and technological literacy

- Information: search literacy, information literacy, tagging literacy

- Connections: personal literacy, network literacy, participatory literacy, cultural and intercultural literacy

- (Re)design: remix literacy

In contrast to the widespread perception that digital skills can be reduced to technical skills, or competence in using information and communication technologies, this taxonomy underscores the idea that digital literacies or new media literacies go beyond simple knowledge of technicality to adaptation in serving one's purposes. As Dudeney \& Hockly (2016) put it:

Knowing how to use Facebook is a skill; knowing how to use it to build a community of likeminded individuals and use that community for professional and personal development is a literacy. (p. 117)

Drawing on Gilster's (1997) work, Tang and Chaw (2016) provide a further example highlighting this distinction between digital literacy and technological competence:

[T] o be digitally literate, one does not just know how to find information from the web, but also has the ability to understand and assemble information from different print or digital sources. Digital literacy involves the mastery of ideas and is not just about using the technology itself. (p. 56)

Considering the difference between digital literacy and digital competence, Janssen et al. (2013) asked the experts to define digital competence. They mentioned that literacy was related to reading and writing and it was valid in the early $90 \mathrm{~s}$, the periods when reading hyperlinked texts was a literacy for the users. Thus, they preferred to use digital competence while describing the abilities of the users. They stated that "competence refers to the categorisation of a discipline in a series of intertwined knowledge, skills and attitudes" (p. 474). At the end of the study, they found twelve digital competence areas varying from general knowledge and skills to privacy and security issues.

In 2013, Ferrari, Punie, and Brečko, who were also among the authors of the aforementioned study, Janssen et al. (2013), published a report on digital competence in Europe. They defined five areas of digital 
competence for the digital citizens: information, communication, content-creation, safety, and_problemsolving. They also proposed a framework for these areas and detailed descriptions for each area. According to this framework, the users of the digital platforms can be categorised as foundation, intermediate and advanced. As for the limitation of their framework, they mentioned that "this remains a conceptual framework, as it has never been piloted nor implemented" (p. 9).

In this paper, the definition of digital literacy was taken from these two perspectives: technical and functional skills. As researchers, we attempted to include technical skills (how to use digital tools) and functional skills (how to use these tools for professional and personal benefit). We specifically focused on digital literacies for language teachers.

\section{Digital literacy practices in language education}

In 1999, Tapscott coined the phrase Net Generation which evoked the idea that the new generation would be competent users of new technologies because they are inseparable from their digital gadgets in all aspects of their lives with increasingly frequent use of their mobile phones. Likewise, Prensky's (2001) seminal distinction between digital natives and digital immigrants suggested that digital natives, individuals who were born into the digitally connected world, would intuitively be competent users of technology, whereas digital immigrants had to learn how to integrate technologies into their practices to become skilful users. A decade later, White and Le Cornu (2011) challenged this distinction and proposed that the principal factor that distinguished digital skills was not age, but time and effort. They, thus, suggested the terms digital residents and digital visitors.

However, almost 20 years after Prensky's (2001) identification of digital natives, those natives do not seem to have become digital residents yet. This is perhaps because despite their large-scale infiltration into our everyday lives, digital technologies do not seem to have achieved normalisation (Bax, 2003), particularly in formal and professional contexts. Several researchers have argued that the everyday social skills for participation in online communities and use of new technologies for meaning-making do not naturally transfer to or are not directly applicable in formal, professional settings (see Selwyn, 2009). This is certainly true in educational contexts. Individuals develop cultures-of-use around digital tools they employ in their everyday practices, which may not comply with the use of such tools in educational contexts (Hampel 2014). In other words, although language learners may know how to employ and manipulate digital technologies to suit their aspirations in informal settings defined by the semiotic affordances and constraints imposed by a given platform, they may still lack the skills to transform the "practical, social use of technology to a more rigorous, pedagogical use" (Dudeney \& Hockly, 2016, p. 116) and need to be trained for effective, reflective and critical use of new media in online learning spaces (Hampel, 2014).

According to Dudeney and Hockly (2016), language teachers can facilitate learners' acquisition of digital literacy skills as part of their language learning experience through tasks and activities that incorporate technologies. However, they can only ensure their students' effective engagement with digital literacy skills given they themselves are digitally literate. Therefore, they argue that pre- and in-service teacher education programmes should not only aim to equip teachers with necessary technical skills, but also with an understanding of the technologies, their importance, and how to employ them in language teaching.

\section{Measuring digital literacy practices of pre-service language teachers}

The plethora of definitions and conceptualisations of what digital literacies mean reflect on the diversity in tools that aim to measure digital literacy practices. One such tool is the digital literacy survey (http://www.digitalliteracy.eu) developed specifically for the European citizens and by the European Computer Driving Licence (ECDL) foundation. In this survey, there are two sections - first section includes questions for the perceptions of the participants, the second section includes questions for actual practices, but it fails to go beyond measuring technical skills. Likewise, a report prepared by the Australian Council for Educational Research (2016) identifying criteria to guide the development of "a global measure of digital and ICT literacy skills" suggests that due to considerable overlap between the terms digital literacy and ICT literacy, they can be used interchangeably. Similarly, Tyger (2011) develops a perceived digital literacy scale to measure teacher candidates' digital literacy, yet the scale items only ask participants' understanding of several ICT terms, such as spyware, weblog, tagging, hence focusing only on perceived ICT knowledge. Other similar instruments also use ICT competence scales (e.g., Hsu, 2010; Tondeur et al., 
2017). A report written by Covello (2010) for a research project titled Analysis for Human Performance Technology Decisions demonstrates this tendency to focus on ICT skills for the measurement of digital literacies as well as the necessity to revise existing instruments regularly as technologies and learners' digital practices continue to evolve.

Given the challenges in defining digital literacies and lack of instruments for measurement beyond ICT competencies, in this paper we explore Turkish PTs' understanding and conceptualisation of digital literacies qualitatively, within a realistic perspective. Our aim is to identify current every day and educational digital literacy practices as well as future training needs of pre-service language teachers for effective incorporation of new media platforms in their teaching. The outcomes of this study are expected to guide revision of language teacher education programs in Turkey and development of appropriate instruments to measure PTs' digital literacies.

\section{Methodology}

\section{Research design}

This study follows a qualitative research design. It identifies PTs' understanding of digital literacies and explores their pedagogical use of digital tools. All participants responded to four open-ended questions via email and a smaller group of students then partook in semi-structured interviews. The responses were analysed qualitatively.

\section{Participants and context}

The participants of this study comprised PTs of English in Turkey. Participants were recruited from English language teaching programs from three universities: (1) Bolu Abant İzzet Baysal University (AIBU), (2) Sivas Cumhuriyet University, and (3) İstanbul University. They are located in different regions of the country; Black Sea Region, Central Anatolia Region, and Marmara Region respectively. The institutions were chosen via convenience sampling, yet it ensured sufficient data collection from different contexts and regions. Demographic information for the participants is presented in Table 1.

As for the participants, 113 senior students from the Departments of Foreign Language Education of these three universities participated in the study in the spring semester of the 2016-2017 academic year. As part of the common curriculum applied in the teacher education programs across the country, all of these PTs had taken a compulsory course in their undergraduate programs, Educational Technology and Material Design, which aims to provide PTs with general information about educational technology and material design. The participants from Bolu Abant İzzet Baysal University were also taking an elective course, Computer Assisted Language Learning, at the time of data collection.

Table 1

The demographics of the participants

\begin{tabular}{lrrr}
\hline University & Total & Male & Female \\
\hline İstanbul University & 51 & 5 & 46 \\
Bolu Abant Izzet Baysal University & 45 & 11 & 34 \\
Sivas Cumhuriyet University & 17 & 5 & 12 \\
Total & 113 & 21 & 92 \\
\hline
\end{tabular}

\section{Data collection procedures}

Data were collected using written open-ended questions. There were five main reasons why open-ended written questions were employed. First, at the time of data collection, available scales and questionnaires for digital literacy were mostly field-specific, and a reliable and valid scale to identify the digital literacy levels of PTs in Turkey did not exist. Second, available digital literacy scales focused heavily on technical ICT skills, which were somewhat tool dependent. Third, the content of the scales predominantly included out-dated tools, some no longer in use. Fourth, a qualitative approach to research design was deemed more appropriate in order to achieve an understanding of participants' perspectives on digital literacies and obtain their own appraisal of their skills. Finally, due to time and resource constraints it was not be feasible to 
conduct face-to-face individual interviews with all the participants. Therefore, the following four openended questions were presented to the PTs via Google Forms:

1. What digital tools do you use? And why? Please give examples.

2. Which social media services do you use? How? For what kind of purposes do you use them (academic, personal issues, just for communication)?

3. How do you think you can use digital tools in teaching English? Please give details with examples.

4. What do you understand from the phrase digital literacy? Would you identify yourself as a digitally literate person? as a digitally literate pre-service teacher? Why/Why not? Please give details and examples.

PTs presented their responses also in written form via Google Forms and were encouraged to explain their responses in detail. Following the analysis of responses on Google Forms, a smaller group of participants were contacted to participate in semi-structured face-to-face interviews. These semi-structured interviews were employed for triangulation purposes and to gain further insight. Forty-three volunteer PTs (7 PTs from Istanbul University and 36 PTs from Bolu Abant İzzet Baysal University) partook in the semi-structured interviews. All the participants who had taken the survey were invited to participate in face-to-face interviews in order to gain a more detailed and comprehensive understanding of the issue. However, only 43 participants (38\%) responded positively. Semi-structured face-to-face interviews with all these PTs were held using semi-structured questions addressed in the survey. The PTs were asked to provide more details about issues raised in the initial stage of data collection in face-to-face interviews. Dudeney and Hockly's (2016) taxonomy was used as the basis for the questions. The interviews provided the researchers with the opportunity to further explore and have an in-depth inquiry of the results received through survey. The following topics were addressed during the interviews:

Table 2

Semi-structured open-ended interview questions

\begin{tabular}{ll}
\hline Main Topic & Sample Question \\
\hline Print literacy & Which online media do you use to interact with your friends? \\
Texting literacy & Family? Instructors? \\
& Do you understand abbreviations used online, such as CU, \\
Hypertext literacy & G8? \\
Visual media and multimedia literacy & Do you create links to other webpages when you write online? \\
& Do you ever create, record and share images, sound files and \\
Gaming literacy & Do you use online games or engage in virtual worlds, such as \\
& second life? How? \\
Mobile literacy & Do you use your mobile phone for educational purposes? \\
& How? \\
Code and technological literacy & Can you change the layout or embed an object in a blog? \\
Search literacy & How do you start searching for any kind of information? \\
Information literacy & How do you evaluate the information you receive online \\
& including social media services? \\
Tagging literacy & Do you classify, label, store and retrieve sites and \\
& information? How? \\
Personal literacy & Do you have an online profile/identity? \\
Network literacy & What kind of groups do you join? Can you give examples? \\
Participatory literacy & Do you write online publicly? Can you give examples? \\
Cultural and intercultural literacy & Do you interact with people from other cultures online? How? \\
Remix literacy & Can you edit images, sound and video files? How? Why? \\
Digital literacies for teaching English & Which technological tools are used by your \\
& instructors/professors at the university? \\
\hline &
\end{tabular}

Data analysis

For the analysis of the data, thematic analysis (Braun \& Clarke, 2006) was conducted. The data were coded in three stages based on Saldaña's (2013) framework for thematic analysis: initial coding, axial coding, and theoretical coding. In the initial coding, all five researchers, independently coded the data with descriptive 
phrases, which leads to all possible directions. In the axial coding, codes were organised into categories and sub-categories so that common points were determined among the researchers. In axial coding, the number of codes was also reduced. In the theoretical coding, the major codes and categories were organised and compared to the "pre-existing theories" (Saldaña, 2013, p. 224), which were previously proposed taxonomies for the digital literacies. All researchers participated in all steps of the annotation and coding simultaneously. This multiple online collaborative coding ensured intercoder reliability of the emerging themes and the trustworthiness of our analyses.

\section{Findings}

In this section, we address each of the research questions. The real names of the participants are not given for the sake of confidentiality and the names presented in the excerpts are pseudonyms.

\section{Research question 1: What does digital literacy mean to pre-service English language teachers?}

Following qualitative analysis, five themes emerged in relation to PTs understanding of digital literacy: (1) embracing new information, (2) digital reading and writing, (3) understanding and using information, (4) creating, sharing and collaborating, and (5) critical thinking and evaluation. The sample data for these codes are presented in Table 3.

Table 3

Sample data for the codes observed

\begin{tabular}{ll}
\hline Code & Sample \\
\hline Embracing new information & $\begin{array}{l}\text { For me digital literacy involves reading widely, } \\
\text { keeping informed, knowing when and how to be } \\
\text { critical and when to embrace new information, } \\
\text { new ideas. } \\
\text { On the basis of this, digital literacy means reading } \\
\text { and writing on the digital era. }\end{array}$ \\
I think digital literacy is understanding of digital \\
Understanding and using information & $\begin{array}{l}\text { tools and using of them effectively and } \\
\text { consciously. }\end{array}$ \\
& $\begin{array}{l}\text { It doesn't mean only using; it means also } \\
\text { understanding and using, creating information and } \\
\text { sharing it. }\end{array}$ \\
& $\begin{array}{l}\text { In my opinion 'digital literacy' is the ability to } \\
\text { use the information, to find the useful } \\
\text { information, to create the information and the } \\
\text { ability to evaluate the information }\end{array}$ \\
&
\end{tabular}

These responses demonstrate that PTs were aware of digital literacy as a concept. They believed that embracing new information and being open to new ideas was one of the characteristics of digitally literate individuals because in order to use digital technologies effectively, individuals need to be open to new perspectives. Some PTs associated the term digital literacy with reading and writing in digital platforms and presented a somewhat limited understanding of the term. Other PTs emphasised the ability to understand and use information in digital platforms effectively and thus implied existence of different levels of digital literacies. The fourth theme observed in the data was about creating, sharing, and collaborating, which are considered among the twenty-first century skills (National Council of Teachers of English, 2013). According to the definition proposed National Council of Teachers of English (2013), active and successful participants of the twenty-first century global society must be able to create, manage, analyse, design, and share information to meet a variety of purposes. A final theme that emerged in the data was related to critical thinking and evaluation and evidenced that some PTs associated digital literacy with criticality. Critical thinking is among the highest level of thinking skills and PTs argued that a digitally literate person should be critical in order to use digital tools effectively.

In addition to providing a definition of digital literacy, PTs were asked to evaluate their own digital literacy skills. PTs comments demonstrated different levels of self-evaluation. Some PTs were confident and had a 
positive appraisal of their level of digital literacy. These PTs predominantly focused on the affective contribution of technologies for themselves and for their students, as demonstrated in the following quotes:

I can identify myself as a digitally literate person. Because I like doing something on computer, learning about new program and using this program. (Seda A.)

I enjoy using digital tools and I think I'm good at this. I like searching new tools, integrate them to the lessons. This makes lessons more enjoyful and attractive. (Gulnur E.)

On the other hand, some PTs did not consider themselves to be digitally literate particularly due to a lack of interest in technologies, a preference towards using more traditional means, and an inability to use digital tools effectively. Examples of these evaluations are captured in the following quotes:

Unfortunately I don't describe myself as digitally literate person because I don't use tools very effectively. I think I am a bit old fashioned, but that doesn't mean that I never use or will never use them. It is just, we are used to use digital tools so we are like, ugh it is hard to prepare, it takes time etc etc. (Seyma B.)

I cannot identify myself as a digitally literate person because I am not interested in technology in my daily life. But I am aware of that I have to use the technology in my classroom, I am not interested but I have to baceuse [sic] my students are interested so I can learn how to use it, because using digital tools is not difficult. (Kubra K.)

The analysis of the semi-structured follow-up interviews provided further support for these findings. Most of the participants evaluated themselves to be digitally literate even though some still preferred traditional methods of teaching and learning. Still, PTs who were interviewed welcomed digital literacy practices and expressed willingness to raise their digital literacy skills to a higher standard before they begin their teaching profession.

PTs perceived competencies in relation to the tasks they can complete in digital platforms related to the following degrees of competence reported in Table 4 . These codes were determined after the axial coding described in the data analysis section so that the number of times mentioned in the data could not be presented.

Table 4

Perceived competencies of PTs

Knowing about digital tools

Knowing about digital tools and digital world

Being able to use digital tools

Being able to use digital tools and communicate using them

Being able to use digital tools for language teaching

Being able to use digital tools for all kinds of purposes

Being able to whatever you want

Being aware of the aims and dangers

These perceived competencies indicated that digital literacy for PTs is not only about having knowledge of digital tools, but also the digital world. Moreover, for PTs digital literacy involved the ability to use digital tools in communication, in teaching and for all kinds of purposes. Finally, criticality was an important aspect of digital literacy in relation to awareness of reasons for and dangers of using digital tools.

It is also important to note that this could be interpreted as some PTs were highly confident and stated that they could do whatever they wanted when they used digital tools. However, this was mitigated by their explanation that they could do everything only with the tools they knew. Whereas this meant that when PTs receive training on the use of the recent tools, they can easily implement them in their future classes, it highlighted the need for in-service training. In a world where new tools appear every day, it is impossible to know and use all the available tools. As new tools are developed and implemented in language teaching, appropriate in-service training plays a key role in sustaining language teachers' confidence levels as regards their digital literacy skills. 


\section{Research question 2: What digital tools do PTs use?}

The second research question in this study investigated the digital tools pre-service teachers used. The variety of digital tools mentioned by the PTs were grouped in relation to their functions. The findings are depicted in Table 5 along with the frequency of mention.

Table 5

Digital tools used by PTs

\begin{tabular}{lr}
\hline The Digital Tools Used & \multicolumn{1}{c}{$f$} \\
\hline Social media tools & 360 \\
Learning management tools & 63 \\
Quiz activities & 37 \\
Material design & 34 \\
Presentation & 17 \\
Online storage & 12 \\
\hline
\end{tabular}

Not surprisingly, the most commonly used digital tools were social media tools, such as Facebook, Twitter, Instagram, and WhatsApp. Almost all students in this study had social media accounts and WhatsApp was installed as a built-in feature on all smart phones. Ninety-seven participants indicated their use of at least one social media tool, whereas 16 participants did not report any use of social media. In our analysis, we counted 360 mentions to a social media tool, which corresponded to three to four different social media tools being used by each PT. Data from the semi-structured interviews corroborated this finding and revealed that almost all PTs had an online profile on various social platforms. PTs stated that they shared, recorded, and created files and/or videos for personal and educational reasons, and were conscious of what and with whom they shared their content.

The second most frequently mentioned digital tools category was learning management systems, with PTs citing for example, Edmodo and Google Classroom. This is one of the most important findings of this study as it indicated that university professors were using these platforms for interacting with students, collecting assignments, and making announcements as these platforms make after-school interactions possible. Semistructured interviews yielded similar results. A large number of PTs acknowledged the fact that they needed the existing online contact with their professors and classmates to access lesson materials, submit assignments, and keep informed about new developments in their courses. Even a small group of PTs who normally preferred print resources and limited online participation expressed the need for online learning management systems.

When responses were examined, it was found that PTs used these tools in their teaching practicum courses and enjoyed using them a lot. Moreover, PTs reported that they learned to use these tools from their professors as they observed them use digital tools in their teaching. Thus, our findings indicate that when university professors integrate digital platforms in their undergraduate classes, PTs became familiar with those tools. However, when professors give lectures without any technological support, the PTs were not offered any opportunities to observe their professors.

Despite the existence of a variety digital platforms for professional development, the number of PTs using digital tools for professional development was low. PTs in our study did not use these platforms and tools in order to improve their teaching and language skills. While most PTs expressed their awareness of various social media platforms and online groups in relation to their professional development, some PTs did not communicate with teachers from other cultures nor develop familiarity with their culture. This could be because communication with teachers from other cultures is not a compulsory component in the courses offered for PTs. Another explanation could be that some PTs might be shy, or that they cannot find the appropriate online communities or reason to communicate with teachers they do not know.

The final two tools that were mentioned by the PTs were presentation tools, for example MS Office Powerpoint and Prezi, and online storage tools. These tools may not have been as prominent as the researchers expected because their use has become normalised (Bax, 2003) and perhaps they are no longer categorised to be a part of the new digital domain but perceived as traditional technology. 


\section{Research question 3: For what specific purposes do PTs use digital tools in teaching English?}

Since the participants of the study were fourth year students and were aware of methodology of language teaching, we aimed to explore the specific purposes for using digital tools for teaching English in the last question. We also asked PTs to project on their future use of digital tools in their professional lives as teachers. Our main concern was about the extent to which PTs could integrate digital tools into teaching platforms. The responses of the PTs were divided into two categories: specific linguistic purposes and pedagogical purposes. Sub-categories for each purpose are presented in Table 6 .

Table 6

Purposes of using digital tools in English language teaching

\begin{tabular}{ll}
\hline Specific linguistic purposes for using digital tools & Pedagogical purposes for using digital tools \\
\hline Skills teaching & Individualising learning \\
Testing and assessing & Promoting autonomous learning \\
Giving and getting feedback & Encouraging motivation \\
Creating exposure & Developing creativity and imagination \\
Modelling target culture & Increasing engagement and participation \\
& Developing group work \\
& Promoting digital design skills \\
\hline
\end{tabular}

The analysis of the semi-structured interviews also provided more information about the purposes of using digital tools. In relation to purposes for use of digital tools to foster specific language skills PTs focused on teaching specific skills. These included employment of a variety of digital tools to teach listening, speaking, reading, and writing, as well as assessment and feedback. Digital tools were also used to provide more exposure to authentic language use and to model the target culture. In terms of other pedagogical purposes, PTs focused on how to improve the educational context for better teaching, for example, increasing the motivation of the students or developing learner autonomy. Digital tools were also used to promote individualised learning, engagement, participation, creativity, imagination, group work, and digital design.

\section{Discussion}

This study sought to identify a realistic definition of digital literacies and pre-service language teachers' appraisal of their digital literacy skills. Dudeney and Hockly (2016) defined digital literacy as "the ability of people to know how to operate these [digital] technologies, and to use them safely, wisely and productively" and "an awareness of the social practices that surround the appropriate use of new technologies" (p. 115). According to the participants of this study, the definition of digital literacies varied. Some PTs only focused on technical skills and being able to read and write online, whereas others demonstrated a wider understanding of digital literacy that extends beyond online reading and writing. For these participants, being digitally literate meant being able to collaborate with others via digital tools and engage in critical thinking. In Dudeney and Hockly's (2016) taxonomy of digital literacy, remixing and creating are among the advanced features of digital literacy. In order to remix or create new information, the individuals need to understand the current information and critically evaluate it to accept or reject the information. This is one of the highest levels of digital literacy. Chappelle (2006, p. vii) also mentioned that "second-language teachers today need to be able to choose, use, and in some cases, refuse technology for their students". In other words, teachers should be knowledgeable and critical enough to appraise the value of technology for their purposes.

As presented in the literature review, a shared understanding of what is meant to be digitally literature has not yet been established. We observed a similar ambiguity in how our participants defined the concept. In light of PTs' understanding of what it means to be digitally literate, it is possible to argue that their selfevaluation of their digital literacy skills reflected the multiple and varied definitions. Whereas some PTs only reported knowledge and use of digital tools, others reported that they could use the tools for purposeful communication with others and in their teaching. Some PTs also showed overconfidence in their skills as well as awareness of the dangers in relation to online safety. However, participants hardly mentioned the need to develop multimodal competencies in online making-meaning (Bezemer \& Kress, 2016) or the ability to establish communities of practice (Lave \& Wenger, 1991). Working with others in collaboration, mostly in online communities of practice is also highlighted in the characteristics of digital literate person 
in the twenty-first century (National Council of Teachers of English, 2013; Theisen et al., 2011) and this should be promoted. We would argue that more research is needed to construct a shared definition of digital literacies in order to guide the teaching of such skills. Likewise, there is a need to establish a framework for evaluation of teachers' literacy development in Turkey.

A second aim of this study was to identify the digital tools PTs used in their personal and academic life, as well as in their initial teaching practices. An exploration of the digital tools used by PTs indicated that they heavily used social media platforms, but also LMSs and quiz activities, either as students at their university courses or as teachers in their practicum schools. This has implications for teacher trainers at universities, indicating they should also be digitally literate and model appropriate practices (c.f. experiential modelling [Hoven, 2006]).

The third research question in this study sought to explore the purposes why PTs used digital tools. PTs mentioned in semi-structured interviews that they used social media tools widely in their personal and professional lives for several purposes, including communication, fun and pleasure, academic, and language learning purposes. They also stated that they could use digital tools in their teaching either as materials to enhance input and skills development or as tools to facilitate motivation, autonomy, creativity, group work, and engagement. These positive outcomes indicate normalisation (Bax, 2003) of the use of digital tools in language teacher training, as well as the success of teacher training programs in Turkey in equipping future teachers with necessary skills (Chun, Smith, \& Kern, 2016) for the future.

\section{Conclusion and recommendations}

With rapid changes in information and communication technologies, it is no longer sufficient for language teachers and PTs to know how to use existing digital tools, but they also need to be digitally literate in order to be able to critically evaluate such tools and platforms for safe, wise, and productive use. In some cases, PTs should be knowledgeable enough to modify existing digital content for their own context, a process which begins during initial teacher education and continues through continued professional development. In this study, we investigated PTs' own conceptualisation of digital literacy. This included an exploration of how PTs defined this concept, what kind of tools they used and for which purposes they preferred to use digital tools. By doing so, we identified the perceptions of PTs in Turkey on their digital literacy levels.

Our findings indicated that PTs were aware of many digital tools and they perceived themselves to be competent enough to use these digital tools for personal, educational, and professional purposes. Their concept of digital literacy seemed to consist of many levels from knowledge to use, and to critical, creative, and collaborative use. While we focused solely on PTs conceptualisation of digital literacy and their perceived use of digital tools, future research can employ observations of actual use or activities in which PTs can be presented with a problem to be solved using digital tools. This could provide a more comprehensive insight into PTs digital literacy levels.

Moreover, we observed that university professors play quite an important role in the development of digital literacy levels of PTs. If the professors use digital tools in their classes, PTs seem to take them as role models and plan to integrate digital tools in their practicum and future teaching. From this perspective, future studies can observe university professors in order to find out to what extent they are digitally literate and integrate technology in their classes.

Another area for future research involves PTs use of social media for professional development. Although some PTs acknowledged social media as a platform for professional development, they would definitely benefit from further guidance in using social media platforms in a variety of ways to become more competent in their profession. Integration of online communities of practice into undergraduate teacher training degrees needs to be considered to increase the digital literacy levels of future language teachers.

This study sheds light on the current digital literacy skills of PTs in Turkey. However, when followed by further studies in other countries, it might contribute to the emergence of a comparative framework that allows for generalisations. It would be beneficial to look at this issue from a broader perspective to explore to what extent the definitions of digital literacy differ from each other; what commonalities or differences exist regarding their digital literacy skills and the types and purposes of digital tools they are using; and whether it is ever possible to reach a common and shared understanding of both the definition and 
components of digital literacy that would inform educational policy makers and teacher trainers to develop teacher training programs. Through an examining such questions, future studies might also contribute to the establishment of a framework for the measurement of digital literacy skills for language teachers.

\section{References}

Australian Council of Educational Research (2016). A global measure of digital and ICT literacy skills. Retrieved from http://unesdoc.unesco.org/images/0024/002455/245577E.pdf

Bax, S. (2003). CALL - Past, present and future. System, 31(1), 13-28. https://doi.org/10.1016/S0346251X(02)00071-4

Bezemer, J., \& Kress, G. (2016). Multimodality, learning and communication: A social semiotic frame. London: Routledge.

Braun, V., \& Clarke, V. (2006). Using thematic analysis in psychology. Qualitative Research in Psychology, 3(2), 77-101. https://doi.org/10.1191/1478088706qp063oa

Chapelle, C. (2006). Foreword. In P. Hubbard \& M. Levy (Eds.), Teacher education in CALL (pp. viiviii). Amsterdam: John Benjamins. https://doi.org/10.1075/11lt.14.01cha

Chun, D., Kern, R., \& Smith, B. (2016). Technology in language use, language teaching, and language learning. Modern Language Journal, 100(S1), 64-80. https://doi.org/10.1111/modl.12302

Covello, S. (2010). A review of digital literacy assessment instruments. Retrieved from http://idmodule.com/research-on-digital-literacy-assessment-instruments-fulltext/

Dooly, M., \& O'Dowd, R. (Eds.) (2012). Researching online foreign language interaction and exchange: Theories, methods and challenges. Bern: Peter Lang. https://doi.org/10.3726/978-3-0351-0414-1

Dudeney, G., \& Hockly, N. (2016). Literacies, technology and language teaching. In F. Farr, \& L. Murray (Eds.). The Routledge handbook of language learning and technology, (pp. 115-126). London: Routledge.

Dudeney, G., Hockly, N., \& Pegrum, M. (2013). Digital literacies. Harlow: Pearson.

Ferrari, A., Punie, Y., \& Brecko, B. N. (2013). DIGCOMP: A framework for developing and understanding digital competence in Europe. Seville: Joint Research Centre.

Gilster, P. (1997). Digital literacy. New York, NY: Wiley.

Godwin-Jones, R. (2015). Contributing, creating, curating: Digital literacies for language learners. Language Learning \& Technology, 19(3), 8-20. Retrieved from http://lt.msu.edu/issues/october2015/emerging.pdf

Hampel, R. (2014). Making meaning online: Computer-mediated communication for language learning. In C., A., Peti-Stanti, \& C. M. Stanojevi (Eds.). Language as information. Proceedings of the Croatian Applied Linguistics Society Conference 2012 (pp. 89-106). Frankfurt: Peter Lang. Retrieved from http://oro.open.ac.uk/38407/

Hoven, D. (2006). Designing for disruption: Remodelling a blended course in technology in (language) teacher education. In L. Markauskaite, P. Goodyear, \& P. Reimann (Eds.). Proceedings of the 23rd Annual Ascilite Conference: Who's Learning? Whose Technology? (pp. 339-349). Sydney: University of Sydney. Retrieved from https://www.scopus.com/record/display.uri?eid=2-s2.0-

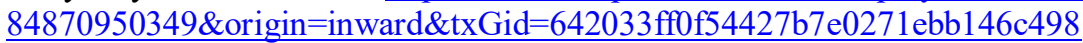

Hsu, S. (2010). Developing a scale for teacher integration of information and communication technology in grades 1-9. Journal of Computer Assisted Learning, 26(3), 175-189. https://doi.org/10.1111/j.1365-2729.2010.00348.x

Janssen, J., Stoyanov, S., Ferrari, A., Punie, Y., Pannekeet, K., \& Sloep, P. (2013). Experts' views on digital competence: Commonalities and differences. Computers \& Education, 68(1), 473-481. https://doi.org/10.1016/j.compedu.2013.06.008

Kern, R. (2014). Technology as pharmakon: The promise and perils of the Internet for foreign language education. Modern Language Journal, 98(1), 295-494. https://doi.org/10.1111/j.15404781.2014.12065.x

Kurek, G., \& Hauck, M. (2014). Closing the 'digital divide' - A framework for multiliteracy training. In J. Pettes-Guikema, \& L. Williams (Eds.). Digital literacies in foreign and second language education: Research, perspectives, and best practice, CALICO Monograph Series 12 (pp.119-140). Texas, TX: CALICO. Retrieved from http://oro.open.ac.uk/42328/

Lankshear, C., \& Knobel, M. (2008). Introduction. In C. Lankshear, \& M. Knobel. (Eds.). Digital literacies: Concepts, policies and practices (pp.1-16). New York, NY: Peter Lang. Retrieved from https://researchonline.jcu.edu.au/27788/1/27788 Lankshear and Knobel 2008.pdf 
Lave, J., \& Wenger, E. (1991). Situated learning: Legitimate peripheral participation. Cambridge: Cambridge University Press. https://doi.org/10.1017/CBO9780511815355

National Council of Teachers of English (2013). The NCTE definition of 21st century literacies. Retrieved from http://www.ncte.org/positions/statements/21stcentdefinition

New London Group (1996). A pedagogy of multiliteracies: Designing social futures. Harvard Educational Review, 66(1), 60-92. https://doi.org/10.17763/haer.66.1.17370n67v22j160u

Pegrum, M. (2011). Modified, multiplied, and (RE-)mixed: Social media and digital literacies. In M. Thomas (Ed.). Digital education: Opportunities for social collaboration (pp.9-35). New York, NY: Palgrave Macmillan. https://doi.org/10.1057/9780230118003 2

Prensky, M. (2001). Digital natives, digital immigrants. On the Horizon, 9(5), 1-6. https://doi.org/10.1108/10748120110424843

Saldaña, J. (2013). The coding manual for qualitative researchers. Thousand Oaks, CA: Sage Publications.

Selwyn, N. (2009). The digital native-myth and reality. Proceedings of Association of Special Libraries \& Information Bureau, 61(4), 364-379. https://doi.org/10.1108/00012530910973776

Tang, C. M., \& Chaw, L. Y. (2016). Digital literacy: A prerequisite for effective learning in a blended learning environment? The Electronic Journal of e-Learning, 14(1), 54-65. Retrieved from https://www.ejel.org/issue/download.html?idArticle=485

Tapscott, D. (1999). Educating the net generation. Educational Leadership, 56(5), 6-11. Retrieved from http://learnwith.tech/ed300/resources/Educating Net Generation.pdf

Theisen, T., Fulton-Archer, L., Smith, M. J., Sauer, T., Small, H., \& Abbott, M. (2011). 21 st century skills world languages map. Retrieved from https://www.actfl.org/sites/default/files/pdfs/21stCenturySkillsMap/p21 worldlanguagesmap.pdf

Thorne, S. L. (2013). Digital literacies. In M. R. Hawkins (Ed.), Framing languages and literacies: Socially situated views and perspectives. (pp. 192-218). New York, NY: Routledge. Retrieved from https://www.researchgate.net/publication/237191470 Thorne_S_L_2013 Digital_Literacies_In_M H awkins ed Framing_Languages_and_Literacies_Socially_Situated_Views_and_Perspectives_pp_192 -218 New York Routledge

Tondeur, J., Aesaert, K., Pynoo, B., van Braak, J., Fraeyman, N., \& Erstad, O. (2017). Developing a validated instrument to measure preservice teachers' ICT competencies: Meeting the demands of the 21st century. British Journal of Educational Technology, 48(2), 462-472. https://doi.org/10.1111/bjet.12380

Tyger, R. L. (2011). Teacher candidates' digital literacy and their technology integration efficacy. (Doctoral dissertation). Georgia Southern University, Statesboro, GA. Retrieved from https://digitalcommons.georgiasouthern.edu/cgi/viewcontent.cgi?article=1557\& context=etd

White, D., \& Le Cornu, A. (2011). Visitors and Residents: A new typology for online engagement. First Monday, 16(9). https://doi.org/10.5210/fm.v16i9.3171

Corresponding author: Sedat Akayoğlu, akayoglu_s@ibu.edu.tr

Copyright: Articles published in the Australasian Journal of Educational Technology (AJET) are available under Creative Commons Attribution Non-Commercial No Derivatives Licence (CC BYNC-ND 4.0). Authors retain copyright in their work and grant AJET right of first publication under CC BY-NC-ND 4.0.

Please cite as: Akayoğlu, S., Satar, M., Dikilitaş, K., Cirit, N. C., \& Korkmazgil, S. (2020). Digital literacy practices of Turkish pre-service EFL teachers. Australasian Journal of Educational Technology, 36(1), 85-97. https://doi.org/10.14742/ajet.4711 